I0,000 individual measurements. He has recently dissected some fifty stools, representing twenty-four varieties, and finds overwhelming evidence that the late canes are the thickest, thus reversing earlier conclusions drawn from the behaviour of the Punjab canes late in the season.

\section{GENERAL PHYSIOLOGY.}

INCRE.ASEI) specialisation brings with it further subdivision of the sciences, and most of the new journals which are founded are restricted to narrower fields than those of existing publications. Now and then, however, an attempt is made to counteract the evils of specialisation by insistence on broad principles and by the provision of a meeting-place for workers in various branches of the same or of kindred subjects. Some such considerations must have led to the recent foundation of the Journal. of General Physiology, which is edited by Prof. Jacques Loeb, a physiologist, and Prof. W. J. V. Osterhout, a botanist, and published by the Rockefeller Institute of Medical Research. This journal, which was referred to in our issue of October 3 I last, is "devoted to the explanation of life-phenomena on the basis of the physical and chemical constitution of living matter," and first appeared in September last. Its scope may, to some extent, be illustrated by a number of reprints which we have received; they are of papers by Prof. Loeb, some physico-chemical, some botanical in nature.

In three papers on amphoteric colloids, which have appeared in the first three numbers of the new journal, Prof. Loeb has continued work previously published by him in the Journal of Biological Chemistry. Contrary to what is generally stated in the literature of colloid chemistry, he concludes that the physical properties of gelatin near the point of neutrality are affected only by the cations of a neutral salt, and not by its anions. "The error into which the colloid chemists have fallen is due to the fact that they alwavs investigated the effect of a neutral salt on a protein in the presence of the salt, while the writer took the precaution to wash the excess of salt away after it had time to act on the gelatin." Accordingly, a quantity of finely powdered gelatin is left for one hour in contact with a neutral salt solution of known concentration. The powder is then filtered off, and the excess of salt removed by reneated washing with water. The gelatin is liquefied by heating to $50^{\circ} \mathrm{C}$., and diluted with water to make a $\mathrm{r}$ per cent. solution. Then, for instance, the osmotic pressure of the solution is determined in a collodion bag. Treatment with salts of a bivalent metal $\left(\mathrm{MgCl}_{2}, \mathrm{CaCl}_{2}\right)$ does not lead to an increase of osmotic pressure, but treatment with sufficiently concentrated solutions of salts of monovalent metals ( $\mathrm{NaCl}, \mathrm{NaCNS}, \mathrm{LiNO}_{3}, \mathrm{Na}_{2} \mathrm{SO}_{4}$ ) results in an increased osmotic pressure. When the powdered gelatin is similarly treated with hydrochloric acid of varying concentrations, it is found that about $\mathrm{N} / 256 \mathrm{HCl}$ (which brings the gelatin to its isoelectric point, $\left.p_{11}=4.7\right)$ makes the total swelling, the osmotic pressure, the conductivity, and the "alcohol number" minima. On the less acid side gelatin is regarded as existing as a negative ion (e.g. gelatin- $\mathrm{H}^{-}$or gelatin$\stackrel{+}{\mathrm{Na}}$ ); on the more acid side as a cation (gelatin- $\mathrm{Cl}$ or gelatin- $\left.-\mathrm{O}^{+}\right)$.

In a later paper the author has determined the amount of bromine in combination with gelatin after treatment with hydrobromic acid of varying concentrations. He regards the curves of osmotic pressure as an "unequivocal function" of the number of gelatin NO. 260 I, VOL. IO4] bromide molecules formed. Prof. Loeb has evidently not seen the recent very careful and elaborate investigation, by Sörensen and his collaborators, of egg-albumin, in the Comptes rendus of the Carlsberg laboratory. A considerable section of this monograph deals theoretically and practically with the osmotic pressure of an amphoteric colloid of great purity in the presence of electrolytes, and takes into account factors which are not dealt with by Prof. Loeb's simple procedure. It will be interesting to see whether, after a perusal of Sörensen's monograph, Prof. Loeb still maintains his somewhat sweeping criticism of colloid chemists.

The botanical reprints are concerned with the mechanism of regeneration in Bryophyllum calycinum. The leaves of this plant possess peculiar dormant buds in each of the notches, which buds may give rise to roots and shoots so soon as the leaf is scparated from the plant. The chemical mechanism of the process is dealt with in a paper in the Annales de l'Institut Pasteur, and is a rare example of work published in English in a French journal. In other papers in the new journal the influence of the mass of a leaf on the quantity of shoots regenerated in an isolated piece of stem is measured, and the phrsiological basis of polarity is discussed. It is suggested that an inhibitory influence of the leaf unon shootformation (as compared with root-formation) is due to inhibitory substances secreted in the leaf, and carried by the sap from the leaf towards the base of the stem.

ATHER AND MATTER: BEING REMARKS ON INERTIA, ANI) ON RADIATION, AND ON THE POSSIBLE STRLCTERE OF ATOMS. ${ }^{1}$

\section{PART I.-INERTIA.}

$W^{E}$ are each of us flying through space at nineteen miles a second, probably much more. Nothing is propelling us; we continue to move by our own inertia, simply because there is nothings to stop us. Motion is a fundamental property of matter. No piece of matter is at rest in the xether, the chances are infinite against any piece having the particular velocity zero; every bit is moving steadily at some given spered, unless acted on by unbalanced force. Then it is accelerated--changed either in speed or direction, or both.

Is a matter of fact, we, like other bodies on the earth, are acted on by two slight, unbalanced forces-one which makes us revolve round the earth once a day, like a satellite; the other which makes us revolve round the sun once-a year, like a planer or asteroid. Our annual revolution is not because we are attached to the earth; we are not attached, but revolve as independent bodies, and would revolve in just the same time and way if the earth were suddenly obliterated; only then we should find the diurnal revolution transmuted into a twenty-four-hour rotation round our own centres of gravity, and the eccentricity of our annual orbit very slightly changed. In any case, there is no propelling force, only a residual radial force produclng curvature of path.

A railway train, or a ship moving steadily, is likewise subject to no resultant force. Propulsion and resistance balance. The whole nower of an engine, after the start, is spent in overcoming friction. The motion continues solely by inertia. Any steadily moving body is an example of the first law of motion. You need not try to think of a body under no force 1 Amplified from a discourse delivered at the Royal Institution on Friday, February 28, 1919, by Sir Oliver J. Lodge, F.R.S. 